\title{
Crystal Structure of 1,2,4,5-Tetra(3-methylphenyl)hexahydro-1,2,4,5-tetrazine
}

\author{
Tokiwa Matsuyama and Kazuyoshi Seguchi ${ }^{\dagger}$ \\ Department of Human Environmental Sciences, School of Human Environmental Sciences, \\ Mukogawa Women's University, Nishinomiya 663-8558, Japan
}

\begin{abstract}
The title compound was synthesized and its structure was characterized by X-ray diffraction. This compound crystallizes in monoclinic, space group $P 2_{1} / n$ with cell parameters of $a=13.1058(14) \AA, b=5.6499(6) \AA, c=16.7410(17) \AA, \beta=$ $103.839(6)^{\circ}$, and $Z=2$; the final residual factor is $R=0.0380$ for 1989 reflections.
\end{abstract}

(Received December 22, 2006; Accepted March 28, 2007; Published on web May 21, 2007)

Photocatalytic reactions of dyes have attracted much attention from synthetic and mechanistic aspects in organic chemistry as well as from application to the treatment of waste water from the dye industry. ${ }^{1,2}$ During the course of our continuous<smiles>Cc1cccc(N2CN(c3cccc(C)c3)N(c3cccc(C)c3)CN2c2cccc(C)c2)c1</smiles>

Fig. 1 Chemical structure of the title compound.

Table 1 Crystal and experimental data

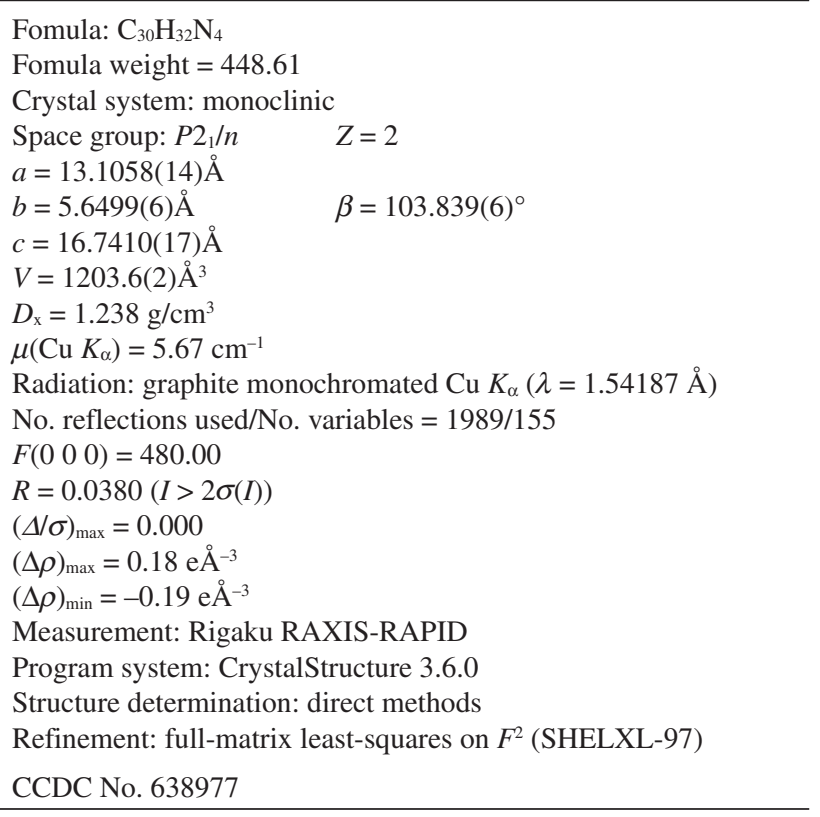

$\dagger$ To whom correspondence should be addressed.

E-mail: seguchi@ mukogawa-u.ac.jp investigation on photocatalytic reactions of 3,3dimethylazobenzene in methanolic suspensions of titanium dioxide, we isolated the title compound (1) (Fig. 1), which different from the reported 1,2,4-triazolidine derivative. ${ }^{1}$ However, conventional analyses by the use of NMR, IR, and MS spectra did not permit identification of the isolated compound.

Compound 1 was prepared as follows: To a suspended solution of 3,3-dimethylazobenzene $(0.24 \mathrm{mmol})$ and Anatase titanium dioxide $(50 \mathrm{mg})$ in methanol $(50 \mathrm{ml})$ in a Pyrex tube was added a drop of acetic acid. The mixture was sonicated for 3 min, and then externally irradiated with a $400 \mathrm{~W}$ highpressure mercury lamp for $4 \mathrm{~h}$ under aerobic conditions. The

Table 2 Final atomic coordinates and equivalent isotropic thermal parameters $\left(B_{\text {eq }}\right)$

\begin{tabular}{ccccc}
\hline Atom & $x$ & $y$ & $z$ & $B_{\mathrm{eq}}\left(\AA^{2}\right)$ \\
\hline $\mathrm{N}(1)$ & $0.49051(8)$ & $0.9887(2)$ & $0.08226(6)$ & $1.61(2)$ \\
$\mathrm{N}(2)$ & $0.55421(8)$ & $0.8192(2)$ & $0.05410(6)$ & $1.65(2)$ \\
$\mathrm{C}(1)$ & $0.48058(9)$ & $1.2080(2)$ & $0.03527(7)$ & $1.62(2)$ \\
$\mathrm{C}(2)$ & $0.40425(9)$ & $0.8852(2)$ & $0.10718(7)$ & $1.55(2)$ \\
$\mathrm{C}(3)$ & $0.30499(9)$ & $0.9892(2)$ & $0.09079(7)$ & $1.71(2)$ \\
$\mathrm{C}(4)$ & $0.22237(9)$ & $0.8868(2)$ & $0.11818(7)$ & $1.83(2)$ \\
$\mathrm{C}(5)$ & $0.2396(1)$ & $0.6761(2)$ & $0.16229(8)$ & $1.95(2)$ \\
$\mathrm{C}(6)$ & $0.3388(1)$ & $0.5724(2)$ & $0.17964(8)$ & $1.94(2)$ \\
$\mathrm{C}(7)$ & $0.4209(1)$ & $0.6754(2)$ & $0.15300(7)$ & $1.72(2)$ \\
$\mathrm{C}(8)$ & $0.1165(1)$ & $1.0066(3)$ & $0.09772(9)$ & $2.41(3)$ \\
$\mathrm{C}(9)$ & $0.66236(9)$ & $0.8184(2)$ & $0.09517(7)$ & $1.64(2)$ \\
$\mathrm{C}(10)$ & $0.7281(1)$ & $0.6425(2)$ & $0.07582(8)$ & $1.77(2)$ \\
$\mathrm{C}(11)$ & $0.8340(1)$ & $0.6303(2)$ & $0.11672(8)$ & $1.95(2)$ \\
$\mathrm{C}(12)$ & $0.8738(1)$ & $0.7934(3)$ & $0.17896(8)$ & $2.14(2)$ \\
$\mathrm{C}(13)$ & $0.8083(1)$ & $0.9644(3)$ & $0.19933(8)$ & $2.19(2)$ \\
$\mathrm{C}(14)$ & $0.7031(1)$ & $0.9789(2)$ & $0.15798(8)$ & $1.90(2)$ \\
$\mathrm{C}(15)$ & $0.9036(1)$ & $0.4422(3)$ & $0.09365(9)$ & $2.55(3)$ \\
\hline $\mathrm{Be}$ & &
\end{tabular}

$B$ eq $=(8 / 3) \pi^{2}\left(U_{11}\left(a a^{*}\right)^{2}+U_{22}\left(b b^{*}\right)^{2}+U_{33}\left(c c^{*}\right)^{2}+2 U_{12} a a^{*} b b^{*} \cos \gamma+\right.$ $\left.2 U_{13} a a^{*} c c^{*} \cos \beta+2 U_{23} b b^{*} c c^{*} \cos \alpha\right)$. 
Table 3 Selected bond lengths $(\AA)$ and bond angles $\left({ }^{\circ}\right)$

\begin{tabular}{|c|c|c|c|c|c|c|c|}
\hline atom & atom & \multicolumn{2}{|c|}{ length } & atom & atom & \multicolumn{2}{|c|}{ length } \\
\hline$N(1)$ & $\mathrm{N}(2)$ & \multicolumn{2}{|c|}{$1.423(2)$} & $\mathrm{N}(1)$ & $C(1)$ & \multicolumn{2}{|c|}{$1.457(2)$} \\
\hline$N(1)$ & $\mathrm{C}(2)$ & \multicolumn{2}{|c|}{$1.421(2)$} & $N(2)$ & $C(1)^{\star}$ & \multicolumn{2}{|c|}{$1.464(1)$} \\
\hline $\mathrm{N}(2)$ & C(9) & \multicolumn{2}{|c|}{$1.420(1)$} & $C(4)$ & $C(8)$ & \multicolumn{2}{|c|}{$1.508(2)$} \\
\hline$C(9)$ & $C(14)$ & \multicolumn{2}{|c|}{$1.395(2)$} & $C(11)$ & $C(15)$ & \multicolumn{2}{|c|}{$1.510(2)$} \\
\hline atom & atom & atom & angle & atom & atom & atom & angle \\
\hline $\mathrm{N}(2)$ & $N(1)$ & $\mathrm{C}(1)$ & $112.2(1)$ & $N(2)$ & $N(1)$ & $\mathrm{C}(2)$ & $113.1(1)$ \\
\hline$C(1)$ & $N(1)$ & $C(2)$ & $122.3(1)$ & $N(1)$ & $\mathrm{N}(\mathfrak{2})$ & $C(1)^{*}$ & $110.20(9)$ \\
\hline$N(1)$ & $\mathrm{N}(2)$ & $\mathrm{C}(9)$ & $116.03(9)$ & $C(1)$ & $\mathrm{N}(2) *$ & $C(9)^{*}$ & $121.7(1)$ \\
\hline$N(1)$ & $C(1)$ & $N(2)^{*}$ & $115.3(1)$ & $\mathrm{N}(1)$ & $C(2)$ & $C(3)$ & $122.7(1)$ \\
\hline$N(1)$ & $C(2)$ & $\mathrm{C}(7)$ & $118.6(3)$ & $N(2)$ & $C(9)$ & $C(10)$ & $119.2(1)$ \\
\hline
\end{tabular}

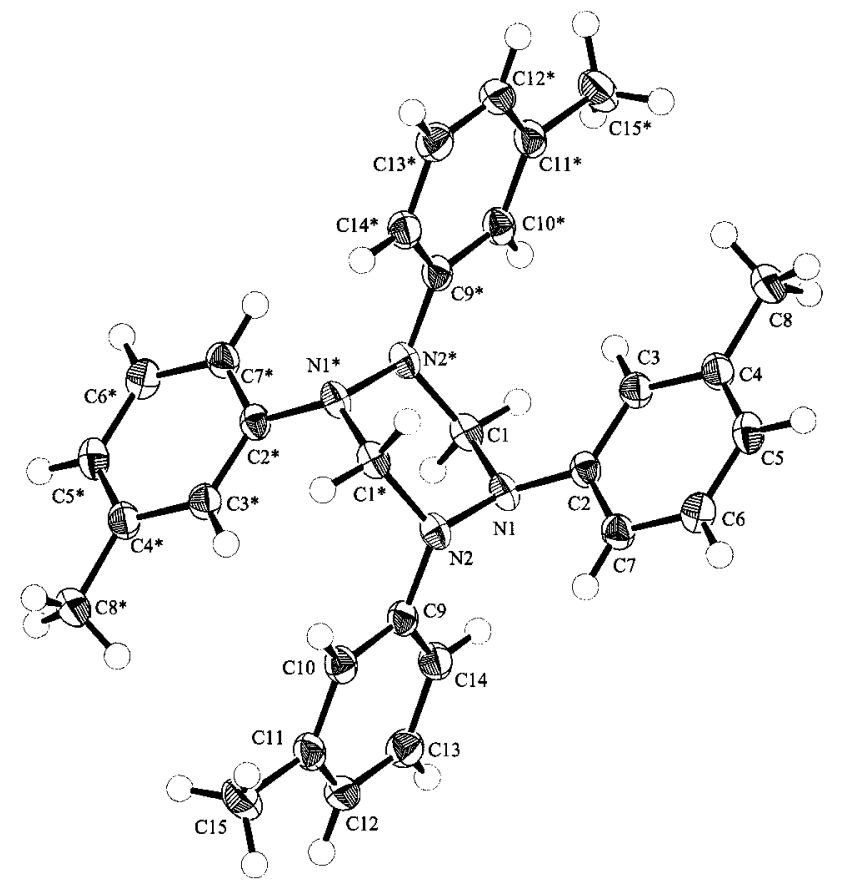

Fig. 2 ORTEP drawing of the title compound along with the atomic labeling scheme. completion of the reaction was indicated by a disappearance of the original orange color. After replacing the solvent by dichloromethane, titanium dioxide powder was filtered off through absorbent cotton, the filtrate was concentrated, and then the residue was washed with ethanol to give 1 in $43 \%$ yield. Careful recrystallization from ethanol afforded crystals appropriate for X-ray analysis.

The X-ray analysis of a colorless crystal $(0.32 \times 0.20 \times 0.20$ $\mathrm{mm}$ ) was performed on a Rigaku RAXIS RAPID imaging area detector with graphite-monochromated $\mathrm{Cu} K_{\alpha}$ radiation $(\lambda=$ $1.54187 \AA$ ). The detailed measurement conditions and the crystal data are listed in Table 1 . The intensity data were collected at $103 \mathrm{~K}$ to a maximum $2 \theta$ value of $136.4^{\circ}$. Of the 11602 reflections collected, 2192 were unique $\left(R_{\text {int }}=0.022\right)$.

The crystal structure was solved by direct methods and expanded using Fourier techniques. The non-hydrogen atoms were refined anisotropically. The hydrogen atoms were located by a geometrical calculation and refined using the riding model. The refined atomic parameters and equivalent isotropic temperature factors for the non-hydrogen atoms are given in Table 2. The selected bond lengths and bond angles are given in Table 3. An ORTEP drawing of compound $\mathbf{1}$ is illustrated in Fig. 2.

The structure of 1 consists of a hexahydro-1,2,4,5-tetrazine skeleton, which exhibits a centrosymmetric chair conformation [torsion angle in the chair conformation; N2-N1-C1-N2*, $-52.7(2)^{\circ} ; \quad \mathrm{N} 1-\mathrm{C} 1-\mathrm{N} 2{ }^{*}-\mathrm{N} 1 *, \quad 51.7(2)^{\circ} ; \quad \mathrm{C} 1-\mathrm{N} 2{ }^{\circ}-\mathrm{N} 1{ }^{*}-\mathrm{C} 1 *$, $\left.50.0(1)^{\circ}\right]$. Four $N$-phenyl groups occur in the axial position, as unexpected from the conformations reported for tetra- $N$ alkylhexahydrotetrazines by the NMR technique ${ }^{3}$ and X-ray analysis. ${ }^{4}$ The dihedral angle between the least-squares planes of two adjacent phenyl rings at $\mathrm{N} 1$ and N2 is $77.2(3)^{\circ}$. The bond lengths of the hexahydrotetrazine ring are in agreement with the reported values for the $\mathrm{C}-\mathrm{N}$ and $\mathrm{N}-\mathrm{N}$ bonds. ${ }^{4}$

\section{References}

1. K. Shibata, T. Mimura, M. Matsui, T. Sugiura, and H. Minoura, J. Chem. Soc. Chem. Commun., 1988, 1318.

2. M. Saquib and M. Muneer, Color. Technol., 2002, 118, 307.

3. S. F. Nelsen and P. J. Hintz, J. Am. Chem. Soc., 1972, 94, 3138.

4. R. Spagna and V. Vaciago, Acta Cryst., 1978, B34, 993. 